\author{
Submission for Special issue of: \\ Interactions: Studies in Communication \&Culture \\ 'Childhoods in transition: mediating "in between spaces", \\ Edited by Richard Berger and Annamária Neag
}

\title{
The 'Undocuqueer' movement and DREAMers: activist online space and the affective queer body
}

By Christopher Pullen and Ieuan Franklin

\begin{abstract}
:
This paper explores the advent of the ‘Undocuqueer’ movement, an activist social network that represents the life chances of undocumented queer youth migrants in the USA, arguing for acceptance, equality and integration, with a particular focus on needs for education. Considering the promise of the DREAM (Development, Relief and Education for Alien Minors) Act (a possible legislative act that would offer education to undocumented migrant youth), this paper offers an historical and cultural foundation as to the emergence of the Undocuqueer movement, and also theoretical insight into the use of online technology utilising 'transmedia testimonio' (Zimmerman 2016). Relating the significance of the affective queer body, this paper contextualises the work of Sara Ahmed with regards to queer phenomenology, arguing that the online work of the Undocuqueer movement, offers a model for queer activism, framing the performative potential of undocumented queer youth, attempting to gain civil rights.
\end{abstract}

Keywords: Undocumented, Queer, Youth, Migrants, Transmedia 


\section{Introduction}

Mateo, a lesbian Cuban-born (late teen) youth activist who identifies as 'he/him', contributes to the 'Undocuqueer’ movement (YouTube 2019a) through posting a video to the YouTube channel Them (YouTube 2019b). He presents himself as a regular citizen within the urban environment of New York City, appearing with a female romantic partner. At points appearing hand in hand with arms around each other, whilst gazing fleetingly into each other's eyes (as lovers do), they traverse the urban environment unhindered. Appearing walking along the streets, then commuting on the subway, travelling on the train and on the escalator, these images are accompanied with Mateo’s voiceover:

What I did when I first moved here, [was that] I told my mom that I was a lesbian. It was right after my birthday. I was like - let me say this right now, so they don't send me back to Colombia, and say that it was the United States that made me gay. Because I had heard stories like that, and I didn’t want it to be the case. (YouTube 2019a)

Mateo’s confident image of mobility and assurance with his lover, evokes key elements of the Undocuqueer movement: that identifying as queer and undocumented is contiguous with the struggle for liberty that might be offered in the United States, whilst also referencing pressures from family, or at least highlighting stereotypical attitudes to queer identity at home.

Mateo's online activism as part of the Undocuqueer movement is contextual to the work of the "DREAMers” (Gamber, Thompson and Zimmerman 2016). These are activists responding to the promise of The DREAM Act (Development, Relief and Education for Alien Minors Act), a potential legislative bill, that since 2001 has been presented to Congress 
in varying forms, and has yet to achieve full passage. ${ }^{1}$ If the DREAM Act does pass it would grant legal status to certain undocumented migrants who were brought to the United States as children and went to school there. The inter relation between the Undocuqueer movement and the DREAMers is significant in this paper, as the former frames the political action of immigrant queer citizens who argue for rights, often by 'coming out' as queer and undocumented at the same time, making themselves doubly vulnerable, while the latter more broadly involves aspirations to achieve citizenship, irrespective of identity politics.

Hence the precarity of being undocumented is linked to the struggles of queer citizens and the transformative possibility of coming out, framing the potential of storytelling as a discursive and political means to improve immigrants’ civil rights (Bishop 2019). However, as Caitlin Ryan and Donna Futterman (1998) tell us:

[S] exuality holds different meanings [and] is shaped by various factors. ... For members of ethnic minority groups, race and ethnicity form core components of identity; together with gender and sex roles (also culturally based), they frame an evolving sense of self. (13)

Undocumented queer youth of diverse ethnicity are often 'required to manage more than one stigmatised identity, which increases their level of vulnerability and stress' (14), and as a consequence although transformative potential is offered through coming out, they can face pressures from family and community for failing to follow traditional sexuality and gender roles, while seeming to disrespect religious beliefs. Despite their vulnerability, undocumented queer youth are willing to use their personal stories in the service of visibility and agency - to enact change.

Hinda Seif (2014) considers the influence of activists Tania Unzeuta and Julio Salgado (discussed further below), in defining the foundation of the Undocuqueer movement in 2010, which stimulated agency from a range of activists: 
This new strategy for the immigrant rights movement ... gave voice to and made visible people who had been objectified as “illegal aliens”. ... Used with tactics such as voter mobilizations and sit-ins inspired by the U.S. civil rights movement, this humanization of undocumented youth was highly effective. (Seif 2014: 88) Undocumented queer youth involve themselves in online activism, producing 'transmedia testimonios' (Zimmerman 2016) as a form of political action, 'that speaks personally about their aspirations and their life chances in finding a new home in the USA, often arriving from Latin America’ (Pullen 2019: 188) as children before adolescence, and later arguing for new citizenship.

In this paper we will examine online contributions to the Undocuqueer movement, framing the significance of 'witness' (Hallas 2009) and 'embodied spectatorship’ in relating the affective queer body (Ahmed 2007). While the transformative potential of online new media is complex, with particular regard to the agency of queer youth that might be considered as a struggle rather than necessarily evidence of power (Berliner 2018), aspects of ambiguity and irony are central in exploring the potential of online media production. This is particularly evident in the iconic graphic poster work of Julio Salgado (2019a), who as a central case study within this paper was a key founder of the Undocuqueer movement. This paper consequently explores cultural intersections and challenges to dominant ideals, in examining the significance of 'transmedia testimonio', also considering the agency of queer youth within transnational contexts (Pullen 2012; 2014). In addition to the foundational work of Julio Salgado, we will assess online contextual work to the Undocuqueer movement, such as Mateo’s romantic urban video (discussed above, and related further below), the poster ‘Los Poets del Norte’ produced by Nico (Tumbler 2020), and content produced by Jorge (YouTube 2019c), within the YouTube Channel Bravenewfoundation (YouTube 2019d). 
Before this, however, it is necessary to consider the theoretical and cultural significance of young immigrants who may identify as queer, suggesting a correlation of diverse political causes. As Natasha Rivera-Silber (2013) tells us:

In many ways, the special relationship between the gay and immigrant rights movements is unsurprising. Both movements are centrally concerned with the boundaries and content of citizenship, with family bonds, and with the pursuit of the American dream. (76)

Hence queer and immigrant rights are inherently bound, particularly with regards to the desire to achieve a sense of identity or acceptance, seemingly offered by the American Dream. However for many migrants and refugees, such attainment or achievement is complicated. Despite the imagined democracy of online new media, which seems to offer potential to those wishing to enter North America or Northern Europe, aspects of bordering remain. As Myria Georgiou (2018) tells us:

[D]igital Europe is deeply implicated in the constitution of bordering power, especially through the complex and contradictory incorporation of refugee and migrant voices. Bordering power [may be considered] as the hierarchical ordering of Europeans’ and migrants’ humanity that subjects migrants to danger, controlled mobility, and conditional recognition. (p.46)

Hence whilst many queer youth migrants engage with digital technologies, seeming to embolden their voices, aspects of gate keeping and border patrolling remain, potentially offering an illusion of equality, with many finding themselves as remaining outside the regular boundaries and borders of community, society and nation, seeming to be 'in between places’.

\section{The In-Between Generation}


There are numerous ways in which young undocumented immigrants occupy 'in-between spaces'. Those who emigrated before adolescence are sometimes referred to as the ' 1.5 generation'. For years they have lived in limbo, with some protected from immediate deportation, but all without the guarantee of any permanent residency or future in the country. In some states they are denied driver's licences and are not allowed to participate in the formal labour market. Lacking access to federal or state financial aid, many are unable to go onto university study (Costanza-Chock 2014: 111). As undocumented youth they are excluded from these crucial elements of citizenship, which themselves play a vital role in how childhood and youth are defined and demarcated. Cockburn has written about how children are, in some respects, 'not citizens' (2012: 1), and it is important to bear in mind that the production and circulation of Undocuqueer public narratives, as discussed in this paper, are themselves a means of claiming or asserting the citizenship denied to them.

Seif (2016: 96) has noted that, at least on a symbolic level, adult immigrants who grew up in the U.S., who are over 30, and are undocumented, may be considered “youth” because they are in ‘developmental limbo’ (a phrase used by Gonzales 2011). This aspect can be contrasted to the youth politics of the 1960s, whereby New Left and civil rights activists represented themselves as youthful as a conscious political choice (Scott 2016: 3). Youth is (already) a special and relatively privileged category within immigration politics. Adults or parents have been presumed guilty - justly or not - with making the 'choice' to immigrate illegally, in migration debates, whereas children have tended to be regarded and depicted as 'innocent' (Seif 2016: 96). We will return to this distinction in due course, but on a broader level this draws attention to the mechanisms of inclusion and exclusion that are more or less invisible to those automatically conferred citizenship and 'adult status'. As Machado Pais explains: 
Traditionally, the concept of citizenship establishes boundaries and margins between societies and groups. ... But the margins are defined from the centre ... on the basis of values which belong to 'us' (the included), as opposed to 'them' (the excluded). (quoted in Quakernack 2016: 125)

This is a prime example of what Mouffe and Laclau term the 'constitutive exclusion' by which any particular notion of inclusion is established (quoted in Butler 2015: 4). A phrase in Spanish that is often invoked within the movement is 'ni de aqui, ni de alla,' (which translates as 'neither from here, nor from there'), which speaks directly to the in-between spaces inhabited by the Undocuqueer movement. This is approximate to Gloria Anzaldua's concept (1987) of nepantla, meaning 'in the middle,' which she has used to describe 'feelings of being caught between multiple cultures, the anxiety experienced, and the new cultures that may emerge from these negotiations’ (Longoria 2018: 22).

Do undocumented immigrants respond by endeavouring to situate or map themselves and their identities using co-ordinates or cardinal points of (un)belonging, citizenship, gender, sexuality, ethnicity and language? Or perhaps, through their activism and aesthetic practices they, as Gayatri Gopinath (2018: 21) posits, 'transform the states of disorientation and suspension that are the by-product of dominant constructions of national and communal (un)belonging into forms of disorientation and suspension that are potentially disruptive and productive'. In the context of highlighting and celebrating queer politics and aesthetics that have the potential to question or challenge the very legitimacy of the nation-state and its immigration and border security regimes (De Genova, cited in White 2014: 977), Gopinath asks:

[W]hat emerges then we see queerness not as homecoming, or as finding our true selves or our proper paths, but as a process of both dwelling in those off-center 
spaces and of staying lost, and thereby perhaps even stumbling into new worlds of possibility. (2018: 54)

Disorientation is the quotidian experience of most undocumented youth, who must navigate the 'tension between their juridical identities as undocumented migrants ... and their subjective identities as US-raised children (an insiderness constituted by growing up in this country)’ (Negrón-Gonzales, quoted in Grattan 2016: 182). It is these experiences of disorientation and confronting the ambiguities of at once belonging and not belonging that have often been channelled productively into art, creativity, and political and media activism.

\section{From DREAMer to Undocuqueer}

An index of this phenomenon can be found in the form of a poster that is popular within the movement. Created by artist and poet Nico of 'Los Poets del Norte', La Dreamer depicts a Latina dressed in the Mexican American chola street style associated with hip-hop and/or gang culture, and carrying a copy of Gloria Anzaldúa’s Borderlands/La Frontera (1987) (see Tumbler 2020). This is a key work in the development of intersectionality as a lived experience and method of inquiry (Cisneros 2018: 1419). As Grattan has noted, Anzaldúa is a hero for many movement activists:

UndocuQueer art and narrative increasingly mirror her unapologetic approach to asserting citizenship: refusing to whitewash racial and cultural identity, mixing English with non-English, and showcasing gender and sexual nonconformity. (Grattan 2016: 186)

In including Anzaldúa’s book the La Dreamer poster is also notable for bringing issues of class, education, and the model/myth of the 'good immigrant' to the fore. Advertising the poster, undocumented blogger Erick Huerta noted ‘not all of us are over-achieving valedictorians, but that also doesn’t mean we're not learnded [sic] folk either... who says 
cholos/as can’t go to college?' ('learnded’ being slang for life experiences gained through 'hood' lifestyles) (Huerta 2012). As Grattan suggests, the poster alludes to friction within the movement, with many Undocuqueer activists dropping the caps and gowns commonly used in their mock 'graduations' to symbolise DREAMer identities (see discussion on Julio Salgado below):

When two NIYA (National Immigrant Youth Alliance) activists staged and filmed their arrest by an Immigration Customs Enforcement (ICE) officer in Alabama in 2011, mainstream DREAMers criticized them for not being "formal” or "articulate”. "Why should I try to impress homeland security,” one responded. "I’m trying to get detained not a fucking scholarship... why should I change the way I speak? I'm from [a Latin American country] raised in the projects in East LA. I'm a hood and proud of it...I do not believe that I should be the "good immigrant” ... to get respect and dignity.” (Grattan 2016: 186)

This is a vivid illustration of the tension between assimilationist and radical approaches, tactics and factions within the movement. In keeping with the broader immigrant rights movement, early DREAM activists 'espoused an assimilationist casting of citizenship that privileged the most exceptional immigrants (e.g. English-dominant and ambitious college students and graduates) as worthy citizens at the expense of Spanish-dominant and less educated immigrants’ (Báez 2016: 420). In this manner DREAMers can be said to have aided in the construction, maintenance, and reproduction of the American Dream, with their emphasis on their education and hard work, and on society's obligation to the next generation (Flores 2015: 2). ${ }^{2}$ As a result concerns have been raised about DREAMer activism delinking undocumented youth from workers (often their own parents) and the larger immigrant rights movement as a whole (Costanza-Chock 2014: 132). Analysis of digital media activism has shown that - partly due to the original failure of the federal DREAM Act - DREAMers are 
relying less on narratives of exceptionalism and 'instead are advocating more inclusively for a moratorium on deportations not only for themselves, but for all undocumented immigrants' (Báez 2016: 424).

To put this into a broader historical context it might be illuminating to revisit the civil disobedience of the civil rights movement in the U.S. in the 1960s, in the form of the famous Greensboro sit-ins of 1960. Ezell Blair Jr, Franklin McCain, Joseph McNeil and David Richmond were all students of North Carolina Agricultural and Technical State University (A\&T), who, on February 1st 1960, attempted to order at the segregated lunch counter of a Woolworths department store, after having made purchases in the shopping department, to highlight the double standards of the establishment. They were refused service because of their race, and performed the nonviolent direct protest method of occupying the space, or sitting-in. As Gitlin remarked, 'Instead of saying that segregation ought to stop, they 'acted as if segregation no longer existed'; they thereby 'threw the burden of disruption onto the upholders of white supremacy’ (Gitlin 1987: 85). The Greensboro sit-in quickly snowballed - by the end of the week they were joined by over three hundred students, and this inaugurated a year of widespread demonstrations, in a hundred cities.

Especially during this period of post-war affluence having the purchasing power to buy material goods itself symbolised the widespread achievement of the American Dream. As Lewis has observed, the 'bombardment of targeted advertising for jeans and movies and music’ reinforced the notion not just of a classless youth culture, but one in which 'generation mattered more than race, that youth itself cut across all the other divisions in American life' (Lewis 2009: 62). But whereas for African American middle-class youth a relative level of affluence meant access to college education and consumer culture, their race prohibited them from actual assimilation into society. ${ }^{3}$ They quickly found that they were 'first-class consumers and second-class citizens' (ibid.), and the sit-ins were a way of 
exposing this in the clear light of day. In some ways this sense of belonging and yet notbelonging is comparable to the situation of undocumented immigrants, who have similarly built a popular movement in response to such societal injustices and contradictions. Both movements have exposed and contested the limits of what Grattan terms 'America's aspirational democratic populist imaginary’ (2016: 186).

Dressed as they were in a smart collegiate style, Rebekah Kowal has argued that the Greensboro students ‘performed their ‘worthiness’ regarding equal treatment by adopting 'white-identified' modes of dress, speech, and behaviour' (Kowal 200: 142), with Ezell Blair making polite, formal responses to the waitress instructing them to leave, such as 'I beg to disagree with you...'. As Rosenthal indicates, such non-violent civil disobedience matched perfectly 'a movement with assimilation objectives' (Rosenthal 1975: 120). The development of civil disobedience as a strategy was pioneered by young student activists, and later in the '60s a new stage in the struggle saw productive but highly fraught coalitionbuilding with other groups affected by discrimination, and the growth of the Black Power movement, who practised a far more radical and confrontational politics.

In many ways there has been a similar chain of developments in undocumented immigration politics. The hope of passing the DREAM Act in 2006 and the struggle to oppose draconian anti-immigrant legislation inspired the political participation of undocumented youth in unprecedented numbers. This has involved marches, hunger strikes, UndocuBus rides, and other acts of civil disobedience (for example, the sit-in staged by undocumented student immigrants at John McCain’s Arizona offices in 2010) that have echoed the civil rights movement. This diversified what had hitherto been an overwhelming emphasis on electoral strategy (voter and citizenship drives) in the immigration rights movement. The influx of young activists resulted in 'national coalitions that emphasised direct action and youth leadership,' (Zimmerman 2016: 1891) and then a grassroots 
Undocuqueer movement which developed a more radical and intersectional analysis. As we have seen, this has highlighted the limitations and dangers of the DREAMer assimilationist casting of citizenship, and as a result many activists have rejected what they clearly regard to be the cap and gown 'performance of worthiness' enacted at DREAM mock graduations and other events.

There is, of course, also a tension between assimilationist and radical approaches or tendencies within the history of LGBT political activism. ${ }^{4}$ Undocuqueer activists often object to what Duggan terms the 'new homonormativity' that has cohered around the marriage equality movement; a 'depoliticised gay culture anchored in domesticity and consumption’ (quoted in Seif 2016: 90). As Jesus Cisneros observes, Undocuqueer immigrants defy the markers of 'progress' as interpreted and ascribed by LGBTQ and immigrant organizations - 'political recognition by officials and institutions that criminalize, incarcerate and deport members of our communities’ (2018: 1430). A compelling recent example of this can be found in the decision by activists from Trans Queer Pueblo (TQP) to protest at the presence of police (the Phoenix Police and Maricopa County Sheriff's Office) and corporate sponsors (Bank of America) at the Phoenix, Arizona Pride parades since 2017. Specifically, Trans Queer Pueblo has criticised Bank of America, the event's main sponsor, for investing money in companies that operate immigration detention centres. ${ }^{5}$

As we have seen, then, identifying as Undocuqueer represented a shift away from the DREAMer narrative (Cisneros 2018, 1426). Cisneros’ interviewees described how identifying as a DREAMer was their doorway into activism, but that, over time, they had become more politicised and developed a critique of the way in which positioning DREAMers as deserving of a pathway to citizenship simultaneously defined who was not. Although the DREAMer identity was initially embraced, it was nevertheless an identity not chosen but instead imposed by legal and political discourse - a 'euphemism for politicians 
who don't want to say the “u” word', as one of Cisnero's respondents called it (Cisneros, op. cit.). As Butler reminds us, this precipitates a questioning process ('am I that name?') that begins the search for 'a better name for the life we wish to live':

We can, and do, ask, “Am I that name?” And sometimes we keep on asking it until we make a decision that we are or are not that name, or we try to find a better name for the life we wish to live, or we endeavor to live in the interstices among all the names. (2015: 61)

The portmanteau word 'Undocuqueer' is a concrete example of the attempt to 'live in the interstices' - like the 'coming out' discourse expressed in videos and blogs produced by the movement, it is an expression of 'their lives at the intersection of immigration laws and nonnormative sexuality’ (Seif 2016: 102). It reclaims and subverts both of these terms 'undocumented' and 'queer' - which have been imposed upon minorities according to sexual and juridical norms that condition 'who will be recognizable and "legible” and who will not' (Butler 2015: 38).

\section{Transmedia Testimonio}

It is important to note that the 'coming out' discourse was not appropriated from outside of gay and lesbian experience (Seif 2016: 102), as LGBTQ youth, with prior experiences of making their sexuality known to others, have long been leading activists in the movement. Coming out as Undocuqueer means coming out twice, and in using self-expression and selfdisclosure as a form of political resistance (Rivera-Silber 2013: 72), these activists are developing forms of becoming visible and legible to one another as well as to those outside the movement. 
There is a growing body of scholarship exploring the innovative use of media by DREAMers and Undocuqueer activists, including the practice of coming out via the testimonio. In its original sense this term refers to a form of auto-ethnography used by subaltern communities in Latin America to contest state power and abuse (Zimmerman 2016: 1887). The Undocuqueer movement has effectively retooled the testimonio for a new generation, using their media literacy to circulate their testimonios across multiple platforms (hence Zimmerman's term 'transmedia testimonio'). Traditional testimonios relied on the mediating figure of the transcriber/translator, which 'limited the agency of the storyteller' because the subject relies upon them to edit and distribute their lived experience (Báez 2016: 422). Transmedia or digital testimonios cut out this middleman and allow individuals to tell and publish their own stories on their own terms (ibid.)

It is also important to acknowledge that the Undocuqueer movement has utilized different kinds of media not just as another platform for activism, mobilisation and public narrative, but also as a means of sharing and developing skills and knowledge. DREAMers and Undocuqueer activists, who have grown up surrounded by digital media and social networking applications, have been active in sharing media-making and communication skills across their networks in formal and informal workshops, as well as online (Costanza-Chock 2014: 139):

Rather than attempt to produce a homogenous message and convince others to disseminate it, they use commercial blogging and video platforms to create spaces for conversation. (ibid.)

This demonstrates the limitations of what Hamilton has called a 'mediacentric' understanding of social change (2008: 252) amongst many activists and scholars within the field of alternative media; the idea that what is needed to transform social relations are simply better (or more effectively didactic) texts. Such positions 'not only assume that the answers to 
political problems have already been found and thus need only to be transmitted, they also underemphasize the importance of more democratic forms of education, research and experimentation’ (Uzelman 2011: 27, citing Hamilton).

Sharing stories online offers undocumented youth a 'recuperative tool' in which to humanize themselves and provide counter-narratives to mainstream portrayals of immigrants (Báez 2016, 421) either as undeserving criminals or as victims. ${ }^{6}$ The 67 Sueños collective (based in San Francisco), for example, uses murals, videos and podcasts to share the stories of undocumented youth, specifically the $67 \%$ of undocumented immigrants that would not be eligible for the DREAM Act due to age limitations and/or the college enrolment or military enlistment required. The collective was created 'in response to the dualistic way that undocumented immigrants are portrayed in mainstream media - cast as either 'good' immigrants that are excellent students seeking to achieve the normative 'American Dream' or 'bad’ immigrants who are criminals and burdens to the state’ (Báez 2016: 427). As Báez continues:

The multimedia storytelling methods of this collective provide counter-narratives to these dualistic depictions of immigrants by foregrounding individual life stories that fall somewhere in the middle of this continuum and are far more complex than dominant images portray. (ibid.)

It is thus also through combatting polarisation that such collectives use digital media and artworks to occupy ‘in-between spaces’ and thereby restore nuance and humanity. The work of 67 Sueños and Julio Salgado (discussed further below) puts a face to undocumented immigrants 'coming out of the shadows' (to use a phrase often deployed by the movement), which counters both their portrayal as invisible statistics by the mainstream media, and the anonymity of much social media activity. It also has a broader cultural significance, given that lived experiences of youth are rarely narrated by young people, and thus youth ceases to 
become merely 'an empty category inhabited by the desires, fantasies and interests of the adult world' (Giroux 2001: 24). Such potential within the Undocuqueer movement, we will argue, frames the performativity of the queer body relative to issues of orientation, whilst referencing the personal experiences of queer youth.

\section{The Affective Body as Witness in the Undocuqueer Movement}

Queer youth migrants involved in activism expose the extent of their vulnerability, establishing themselves as witnesses offering testament to their experiences, whilst encouraging audiences to also witness their emotional landscapes, often revealing abjection and rejection. As Frances Guerin and Roger Hallas (2007) tell us through 'bearing witness, material images do not merely depict the historical world, but [they] participate in its transformation' (4). The Undocuqueer movement encourages participants to share personal stories enabling a collective sense of witness, framing the life world of the queer migrant, while offering the potential for transformation. Narratives of rejection from family, rejection by mainstream community, and the need to achieve basic human rights (such as education), frames not only their situation as 'in-between', but also their vulnerability.

However rather than a relying on 'visibility politics' which might involve an over emphasis on the identity of the mass audience, a focus is paced on the performative body of the storyteller. As Peggy Plelan tells us:

Visibility politics are additive rather than transformational. ... They lead to a stultifying "me-ism" to which realist representation is always vulnerable. Unable to see oneself reflected in the corresponding image of the Same, the spectator can reject the representation as "not about me”. (11) 
Hence in order for queer youth migrants to address mass audiences, there is less of a reliance on identities or necessarily communities, but rather senses of emotional witness are articulated, framing the affective presence of the body. As Roger Hallas tells us:

The relationship between visual media and the witness as superstes - or internal witness [articulates] experience as a form of embodied knowledge. ... [B]earing witness does not center on generating objective evidence, its employment of the visual image does not require the indexicality of photographic technologies. (15) A sense of witness is produced that stimulates co-presence, and a kind of embodied spectatorship. In the manner of Laura U. Marks’ (2000) definition of 'haptic visuality’, where cinematic images evoke a sense of touch, memory and intimacy that does not reply on explicit subjectivity, Undocuqueer youth utilize their emotional universe in bearing witness to the experiences that they have received, also articulating their desires, hopes and aspirations.

As part of this documentary potential, the body of the storyteller is foregrounded, rather than their explicit narrative. This might involve an emphasis on scale or dimension, framing the isolated body of the storyteller within the visual frame, iterating senses of magnitude. As Bill Nichols tells us 'The magnitudes opened up by a text are not merely a matter of naming something of profound importance but, more tellingly of situating the reader in a position where these magnitudes receive subjective intensity’ (232). We argue that the work of the Undocuqueer movement stimulates an embodied sense of spectatorship utilising magnitude and perspective, where the audience experience aspects of witness, testimony and vulnerability, while indicating issues of co-presence and orientation.

If we examine the video 'Undocumented and Unafraid, Queer and Unashamed' produced by Jorge (YouTube 2019c) from the YouTube channel Brave New Foundation (YouTube 2019d) alongside the online iconographic work of Julio Salgado, aspects of isolation are co-present with the positive senses of affirmation. These representations of the 
Undocuqueer movement on the one hand argue for acceptance and equality, and on the other highlights the vulnerability of the body, and issues of orientation.

Jorge’s video 'Undocumented and Unafraid, Queer and Unashamed’ is a self-reflexive documentary-like video, produced in the manner of the 'transmedia testimonio’ (discussed above), featuring Jorge and his mother at home, considering his life as both queer and undocumented. Distributed online as part of social media, Zimmerman (2016) tells us that undocumented students use transmedia testimonio:

... as part of an integrated social movement strategy. ... These digital testimonios are used as a way for undocumented students to participate in counter public spaces where they can invent and circulate discourses and formulate oppositional interpretations of their identities, interests, and needs. (1887) Jorge's testimonio, however, is unlike Mateo’s video (discussed in the introduction), as the production values are more modest, and there are practically no exterior scenes in the city. The focus is on the personal experiences of Jorge, framing responses from his mother, and discussing his father. In contrast to this Julio Salgado’s iconographic artwork (Salgado 2019a) establishes a countercultural identity for the Undocuqueer movement, in a more formal sense of the testimonio. Producing activist posters that frame the narrative experiences of undocumented queer youth, Salgado’s work was foundational for the Undocuqueer movement. We have decided to contrast these two exemplars, as Jorge's video offers an intimate face-to-camera documentary style evoking senses of social realism and authenticity, while Julio’s artwork offers a hyper sense of political realism through utilising the poster form, which may be purchased for consumption. We are not suggesting that one testimonio is more authentic than the other, but that these contextual forms evoke the political ideology of the Undocuqueer movement, highlighting senses of emotion connected to the affective potential of the queer body. 
Jorge's video offers provocative insights into the moment of his political realisation, where he states that:

At times when I walked into a meeting, or went to a rally, I was like, OK, today I am wearing my ‘undocumented’ half only, but not my queer half. I could prove now that there were other queer folks in the room, but they were also not sharing their stories. So I really started questioning that, and putting that responsibility on my shoulders.

Through framing the emergence of the Undocuqueer movement and his agency within it, Jorge not only tells us that he was aware that queer individuals were originally uncomfortable in announcing their sexuality to others within the undocumented community, but also that he frames the separation of these worlds, linking this to the affective potential of his body, through framing a need to take the responsibility 'on his shoulders', and identifying issues of separation or distance.

Such a focus offers resonance to the work of Sara Ahmed relating the affective orientation of the queer body (2007). She tells us:

Orientations shape not only how we inhabit space, but how we apprehend this world of shared inhabitants, as well as "who" or "what” we direct our energy and attention toward. ... Orientations, then, are about the intimacy of bodies and their dwelling places. ... Migration could be described as a process of disorientation and reorientation: as bodies “move away” as well as “arrive,” as they re-inhabit spaces. (39).

Jorge's knowledge that he needed to take action is not necessarily an explicit political action, which occurred in a moment of realisation; it involved an understanding of his bodily orientation, considering his proximity to other bodies, who were silent about their queer identity, and his understanding of how he could use his body. At the same time, the affective 
performance of his body as a queer migrant is framed within the context of his family. This is evident when earlier to this sequence he announces the moment of his realisation for action, at this point Jorge discusses his problematic relationship with his father who rejected him on discovering that he was queer. At the same time Jorge discusses his relationship with his mother, and how she accepts him, but how she finds it hard to fully understand his queer identity. Hence Jorge's articulation of identity is framed within the contexts of both his distance from family, and a need to take the 'responsibility on his shoulders' framing a lack in his queer community. Jorge highlights the need to better understand the affective bodily in relation to the human condition, defining senses of space, or absence of place.

Issues of belonging, and to whom we belong, such as how we fit within our families (or even community) are crucial, but there is also a need to understand how belonging is articulated, relative to our bodily orientations, that might frame identity formations or hierarchies. As Sara Ahmed tells us 'experience of migration makes explicit how we always occupy more than one community’ (158), Jorge articulates the notion of belonging as not where we fit, but rather how we make connections, that reveal disparities, as much as equalities.

Such potential may be equally apparent in the work of Julio Salgado. If we consider his poster 'I challenge you. I challenge me’' (Salgado 2019b), this offers a provocative graphic representation of a queer Latino young man wearing a graduation gown and a mortarboard, as if parodying the potential to gain an education in the United States. However, rather than a conventional image that might offer a clear (if somewhat ironic) argument that undocumented queer youth might be like any other hardworking students, and that these are worthy of gaining citizenship and the right to education, a more controversial image is produced. The image shows the queer male student with his eyes closed and tongue stuck out, wearing his graduation gown sliding back over his shoulders, directly symbolising 
the DREAMer movement (see discussion above), with his crotch proffered just covered with his underpants. This image foregrounds an overweight or 'out of shape' torso with words written across the chest and stomach: "Sometimes I read. Sometimes I protest. Sometimes I draw. Sometimes I fuck. Sometimes I get fucked”. At the same time the background for this image includes three helicopters hovering in the distance, a graphic of a mouth salivating represented in the sky as alongside the helicopters, the hand of the student on an Ionian column, and the separation of the background to reveal a fence. Through foregrounding the figurative body of the undocumented queer youth at the centre of the image, alongside connotations of surveillance, containment, sexual desire, and self-observation, an unstable and almost incoherent, image is produced. Audiences may consider to whom this image is addressed. Is it for the consumption of undocumented queer youth themselves, offering a self-reflexive critique of identity whilst revealing limitations, or inhibitions? Or is it addressed to mainstream audiences, keying into stereotypical ideals that surround undocumented queer youth, offering some disruptive vision that may be stimulating or challenging?

Julio Salgado’s images are available to be purchased, highlighting the consumptive nature of his work. It is produced as a product, as much as a work of art that tells a particular story, revealing its neoliberal significance, in a contemporary world where transactions are more significant than ideologies of care for individuals (Chomsky 1998). While we argue that his work is likely produced for both undocumented queer youth and for mainstream audiences, and he creatively uses processes of neoliberal consumption to engage with diverse audiences who might better learn about social justice through owning his artwork, his affective bodily performance highlights his ability to reach diverse audiences. 
Not unlike Jorge's work (discussed above), it is the relationship between identity and places which forms our understanding, rather than the need to find a destination or achieve an outcome. As Sara Ahmed tells us with regards to fear:

Emotions are directed to what we come into contact with: they move us "toward" and "away" from such objects. So, we might fear an object that approaches us. The approach is not simply about the arrival of an object: it is also how we turn toward that object. The feeling of fear is directed towards that object: while it is also an apprehensive object in a certain way, as being fearsome. The timing of this apprehension matters. For an object to make this impression is dependent on past histories, which surface as impressions on the skin. (2)

The orientations of undocumented queer youth involve complex intersections with personal desires. Salgado’s poster 'I challenge you. I challenge me', frames the queer body as between places, yet does not record the limits or the distances, but abstractly presents the iconographic concerns. Hence the literal skin of the body is inscribed as an impression of history, not with words that record events, happenings or outcomes, but rather with feelings, sentiments, fallibilities and desires. Such an affective image displaces history, and foregrounds emotion, intimating affective senses of the body.

\section{Conclusion}

Undocumented queer youth have creatively used online media resources, as part of the Undocuqueer activist movement, in order to stimulate political messages, as regards needs for acceptance, education and integration. Using the format of the transmedia testimonio, wider audiences have been reached, forming a sense of collective creative action. As part of the DREAMer generation, contributors to the Undocuqueer movement have framed their 
situation as 'in-between places', whilst at the same time utilising processes such as 'coming out' in asserting their visibility and agency.

To disclose one's status as undocumented and queer reveals senses of resolve and strength among the Undocuqueer activists. At the same time, it is clear that media producers such as Mateo, Jorge and Julio Salgado (discussed above) frame issues of bodily orientation, that stimulate affective potential in understanding histories of rejection, and vulnerability. Such processes do not necessarily prescribe what needs to be done, but rather encourages audiences to better understand the situation of undocumented queer youth. Mateo's romance with his partner set within the city, Jorge's reflection on the moment when he realised that he should take action, and Julio Salgado’s provocative political posters, are all part of an affective movement within online media, designed not to educate you that they are different and define what needs to be done, but rather to articulate relationships, activities, concerns, displeasures and pleasures, foregrounding the emotional world of the narrator, as an isolated body in relation to others.

Following Sara Ahmed's ideas on the definition of a queer phenomenology and relationships to the body: 'the skin that seems to contain the body is also where the atmosphere creates an impression; just think of goose bumps, textures on the skin surface, as body traces of the coldness of the air. Bodies may become oriented in this responsiveness to the world around them, given this capacity to be affected’ (p. 9). Undocumented queer youth involved in media production, reveal their vulnerability to mass audiences in this manner. Such potential frames the human condition, as affective and responsive, connected not necessarily to direct political action, but rather to the humanity and the contingency of the producers.

Undocuqueer youth exist 'in limbo’ between places, not seeming to be fixed to terrain. The identities of undocumented and queer youth seem disparate, but connected. 
While the DREAM Act has yet to pass, the longing for changes in legislation bonds those who are working as part of the Undocuqueer movement. Although inevitably the Undocuqueer movement involves complex intersections between assimilation and rebellion, and it's possible to argue that the pursuit of ideal citizenship is fundamentally flawed, undocumented queer youth activists are more likely to be aware of disparities within their communities, and a need to offer access to all, rather than pursue solutions simply for the benefit of themselves. For example, undocumented queer youth coming from developing countries may be doubly stigmatised for their sexuality and their racial/ethnic identity within new homelands, and also maybe rejected by homeland communities and families, yet their conviction to utilise their personal identities within transmedia testimonio, offers transcendent potential, demonstrating care for themselves, and for wider worlds.

Like the struggles of the early LGBT civil rights movement, and those of racial equality, it is the relationship that we build between ourselves that offers strength, rather than an idealistic notion of acceptance or equality. It's clear that the Undocuqueer movement consists of diverse social actors working towards change, not pursuing simplistic answers, solutions and demands, but rather through affective adaptability and persistence, revealing disparities and uneven relationships, that may be sensed as much as defined.

\section{Notes}

\footnotetext{
${ }^{1}$ The progress of the Dream Act is complex. It has not gained full passage, but there are a number of current legislative proposals (see American Immigration Council 2019).

2 This is alluded to or 'spoofed' in the title 'La Dreamer' which, as well as literally meaning 'the dreamer', alludes to the song LA Dreamer by Charlie (1978), a story of a new arrival in the 'town of dreams'.

${ }^{3}$ In terms of sources and argumentation I have drawn here on an excellent undergraduate essay on the civil rights movement by Tom Rayner, who is currently undertaking postgraduate research at Universiteit Utrecht in the Netherlands. Tom Rayner, 'Civil Rights Activism' essay, Unit: Youth Culture and Politics: 1945 to the Present, Bournemouth University, 2017.

${ }^{4}$ Queer undocumented immigrants often point to the continued erasure of the contributions of people of colour in LGBT culture and activism, which can be traced back to the historical
} 
erasure of transgender women of colour - Marsha P. Johnson and Sylvia Rivera - in the original Stonewall movement. This is not merely an issue of history - many activists use their undocuqueer identity to highlight the exclusion of queer undocumented immigrants within and from LGBT debates, spaces and victories (Cisneros 2018, 1425).

5 'Undocumented and LGBT' Podcast No. 1, Latino Media Collective/Latino Rebels Radio. https://www.latinorebels.com/2018/07/11/undocumentedandlgbtq/

${ }^{6}$ Viewing them through this lens of victimhood neglects the important point that 'migrants are not naturally vulnerable, rather the state is deeply implicated in constructing vulnerability through immigrations controls and practices’ (Anderson, Sharma, and Wright 2009, 8). 


\section{References}

Ahmed, Sarah (2007), Queer Phenomenology: Orientations, Objects, Others. Durham: Duke University Press.

Anderson, Bridget, Nandita Sharma, and Cynthia Wright (2009), 'Editorial: Why No Borders?’ Refuge: Canada’s Journal on Refugees 26 (2): 5-18.

American Immigration Council (2109) 'The Dream Act, DACA, and Other Policies Designed to Protect Dreamers', https://www.americanimmigrationcouncil.org/research/dreamact-daca-and-other-policies-designed-protect-dreamers. Accessed 11 October 2019. Anzaldúa, Gloria (1987), Borderlands - La Frontera: The New Mestiza. Aunt Lute Books. Báez, Jillian M. (201), 'Spreadable Citizenship: Undocumented Youth Activists and Social Media.' In The Routledge Companion to Latina/o Media, edited by Maria Elena Cepeda, 419-31. Routledge.

Berliner, L. (2018) Producing Queer Youth: The Paradox of Digital Media Empowerment. Routledge.

Bishop, Sarah. C. (2019), Undocumented Storytellers: Narrating the Immigrant Rights Movement. Oxford University Press.

Butler, Judith (2015), Notes Toward a Performative Theory of Assembly. Harvard University Press.

Cisneros, Jesus (2018), 'Working with the Complexity and Refusing to Simplify: Undocuqueer Meaning Making at the Intersection of LGBTQ and Immigrant Rights Discourses.' Journal of Homosexuality 65 (11): 1415-34. https://doi.org/10.1080/00918369.2017.1380988.

Chomsky, Noam (1998), Profits over People: Neoliberalism and the Global Order. New York, Seven Stories Press

Cockburn, Tom (2012), Rethinking Children’s Citizenship. 2013 edition. Houndmills, Basingstoke; New York: Palgrave.

Costanza-Chock, Sasha (2014), Out of the Closets, Out of the Shadows, and Into the Streets:: Pathways to Participation in DREAM Activist Networks. The MIT Press. https://mitpress.universitypressscholarship.com/view/10.7551/mitpress/97802620282 02.001.0001/upso-9780262028202-chapter-7. 
Flores, Nicholas (2015), 'DREAMing the 'Right' Way: The Cultural Politics of the DREAM Act and UndocuQueer Social Movements.’ The Ohio State University. https://etd.ohiolink.edu/pg_10?0::NO:10:P10_ACCESSION_NUM:osu1429038667.

Giroux, Henry A. (2001), Stealing Innocence: Corporate Culture’s War on Children. 2000 edition. New York, NY: Palgrave Macmillan.

Georgiou, Myria. (2018) Does the subaltern speak? Migrant voices in digital Europe, Popular Communication 16 (1): 45-57.

Gitlin, Todd (1987), The Sixties: Years of Hope, Days of Rage. Bantam Books.

Gonzales, Roberto G. (2011), 'Learning to Be Illegal: Undocumented Youth and Shifting Legal Contexts in the Transition to Adulthood.' American Sociological Review 76 (4): 602-19. https://doi.org/10.1177/0003122411411901.

Gopinath, Gayatri (2018), Unruly Visions: The Aesthetic Practices of Queer Diaspora. Durham: Duke University Press.

Grattan, Laura (2016), Populism’s Power: Radical Grassroots Democracy in America. Oxford, New York: Oxford University Press.

Guerin, Frances and Hallas, Roger (2007), The Image and the Witness: Trauma, Memory, and Visual Culture, London, Wallflower Press.

Hallas, Roger (2009), Reframing Bodies: AIDS, Bearing Witness, and the Queer Moving Image. Durham: Duke University Press.

Hamilton, James Frederick (2008), Democratic Communications: Formations, Projects, Possibilities. Lexington Books.

Huerta, Erick (2012), ‘'La Dreamer’ Poster Available for Purchase.’ March 29, 2012. http://www.elrandomhero.com/2010/05/support-cause-and-buy-poster.html.

Kowal, Rebekah J. (2004), 'Staging the Greensboro Sit-Ins.' TDR/The Drama Review 48 (4): 135-54. https://doi.org/10.1162/1054204042442008.

Lewis, Andrew B. (2009), The Shadows of Youth: The Remarkable Journey of the Civil Rights Generation. Farrar, Straus and Giroux.

Longoria, Anthony (2018), ‘Beyond Butterflies: The UndocuQueer Movement, Intersectionality, and Implications for Education.' Seattle: University of Washington.

Marks, Laura U. (2000), The Skin of Film: Intercultural Cinema, Embodiment, and Senses. Durham: Duke University Press.

Nichols, Bill (1994), Representing Reality: Issues and Concepts in Documentary. Indiana University Press. 
Pullen, Christopher (2019), 'Queer Youth Refugees and the Pursuit of the Happy Object: Documentary Technology and Vulnerability', in Peter Aggleton, Rob Cover, Deanha Leahy, Daniel Marshalland Mary Lou Rasmussen (eds), Youth Sexuality and Citizenship, London: Routledge, 184-200.

Pullen, Christopher (ed) (2014), Queer Youth and Media Cultures, Basingstoke: Palgrave MacMillan.

Pullen, Christopher (ed) (2012), LGBT Transnational Identity and the Media, Basingstoke: Palgrave.

Quakernack, Stefanie (20160, ‘(Re-)Framing Testimonio on YouTube: Multimodal Performances of Dispossession in Digital Narratives of Undocumented Youth.' Universität Bielefeld. https://pub.uni-bielefeld.de/record/2902068.

Rivera-Silber, Natasha (20130, 'Coming out Undocumented in the Age of Perry.' New York University Review of Law \& Social Change 37: 71-78.

Rosenthal, Joel (1975), “Southern Black Student Activism: Assimilation vs. Nationalism.” The Journal of Negro Education 44 (2): 113-29. https://doi.org/10.2307/2966647. Ryan, Caitlin and Futterman, Donna (1998), Lesbian and Gay Youth: Care and Counseling, New York, Columbia University Press.

Salgado, Julio (2019a), https://juliosalgadoart.bigcartel.com/. Accessed 9 October 2019. Salgado, Julio (2019b), https://juliosalgadoart.bigcartel.com/product/i-challenge-you-ichallenge-me. Accessed 9 October 2019.

Scott, Holly V. (2016), Younger Than That Now: The Politics of Age in the 1960s. University of Massachusetts Press.

Seif, Hinda (2016), “'Coming out of the Shadows’ and 'Undocuqueer’: Undocumented Immigrants Transforming Sexuality Discourse and Activism.’ In Queering Borders: Language, Sexuality, and Migration, edited by David A. B. Murray. John Benjamins Publishing Company.

Tumbler (2020), Loteria Art. La Dreamer: Art by 'Nico of Los Poets del Norte’” https://loteriart.tumblr.com/post/13602508845/la-dreamer-art-by-nico-of-los-poetsdel-norte. Accessed 16 January 2020

Uzelman, Scott (2011), 'Dangerous Practices: ‘Determinism of Technique’ in Alternative Media and Their Literature.’ Text. March 2011. https://doi.org/info:doi/10.1386/mcp.7.1.21_1.

White, Melissa Autumn (2014), 'Documenting the Undocumented: Toward a Queer Politics of No Borders.' Sexualities 17 (8): 976-97. G. 
YouTube (2019a), 'What it's Like to be Queer and Undocumented | First Person | them', https://www.youtube.com/watch?v=CfwDflt9aLQ. Accessed 9 October 2019.

YouTube (2019b), 'Them',

https://www.youtube.com/channel/UCZEL_lFVOcFVlmjhguk0IxQ. Accessed 9 October 2019.

YouTube (2019c), 'Undocumented and Unafraid, Queer and Unashamed'

https://www.youtube.com/watch?v=kIi3cPArnDU\&list=PLpcK6aelw4n2D5E3CldFD 1paq2BK5P-Qt. Accessed 9 October 2019.

YouTube (2019d), 'Brave New Foundation'

https://www.youtube.com/user/bravenewfoundation. Accessed 9 October 2019.

Zimmerman, Arely (2016), “Transmedia Testimonio: Examining Undocumented Youth’s Political Activism in the Digital Age.” International Journal of Communication 10 (0): 21. 